University of Nebraska - Lincoln

DigitalCommons@University of Nebraska - Lincoln

USDA National Wildlife Research Center - Staff Publications
U.S. Department of Agriculture: Animal and Plant Health Inspection Service

$10-2012$

\title{
Survey of gastrointestinal parasite infection in African lion (Panthera leo), African wild dog (Lycaon pictus) and spotted hyaena (Crocuta crocuta) in the Luangwa Valley, Zambia
}

\author{
Are R. Berentsen \\ USDA National Wildlife Research Center, Are.R.Berentsen@aphis.usda.gov \\ Matthew S. Becker \\ Montana State University - Bozeman, matt@zambiacarnivores.org \\ Heather Stockdale-Walden \\ University of Florida College of Veterinary Medicine, hdstockdale@ufl.edu \\ Wigganson Matandiko \\ Montana State University - Bozeman \\ Rachel McRobb \\ South Luangwa Conservation Society \\ See next page for additional authors \\ Follow this and additional works at: https://digitalcommons.unl.edu/icwdm_usdanwrc \\ Part of the Life Sciences Commons
}

Berentsen, Are R.; Becker, Matthew S.; Stockdale-Walden, Heather; Matandiko, Wigganson; McRobb, Rachel; and Dunbar, Mike R., "Survey of gastrointestinal parasite infection in African lion (Panthera leo), African wild dog (Lycaon pictus) and spotted hyaena (Crocuta crocuta) in the Luangwa Valley, Zambia" (2012). USDA National Wildlife Research Center - Staff Publications. 1100.

https://digitalcommons.unl.edu/icwdm_usdanwrc/1100

This Article is brought to you for free and open access by the U.S. Department of Agriculture: Animal and Plant Health Inspection Service at DigitalCommons@University of Nebraska - Lincoln. It has been accepted for inclusion in USDA National Wildlife Research Center - Staff Publications by an authorized administrator of DigitalCommons@University of Nebraska - Lincoln. 


\section{Authors}

Are R. Berentsen, Matthew S. Becker, Heather Stockdale-Walden, Wigganson Matandiko, Rachel McRobb, and Mike R. Dunbar 


\title{
Survey of gastrointestinal parasite infection in African lion (Panthera leo), African wild dog (Lycaon pictus) and spotted hyaena (Crocuta crocuta) in the Luangwa Valley, Zambia
}

\author{
Are R. Berentsen ${ }^{*}$, Matthew S. Becker², Heather Stockdale-Walden ${ }^{3}$, \\ Wigganson Matandiko ${ }^{4}$, Rachel McRobb ${ }^{5} \&$ Mike R. Dunbar ${ }^{1^{\ddagger}}$ \\ ${ }^{1}$ USDA/APHIS/WS/National Wildlife Research Center, 4101 LaPorte Avenue, Fort Collins, Colorado, U.S.A., 80521 \\ ${ }^{2}$ Zambian Carnivore Programme, P.O. Box 80, Mfuwe, Eastern Province, Zambia / Department of Ecology, Montana State \\ University, Bozeman, Montana, U.S.A., 59717 \\ ${ }^{3}$ University of Florida College of Veterinary Medicine, Department of Infectious Diseases and Pathology, 1945 SW 16 th \\ Avenue, V2-155, Gainesville, Florida, U.S.A., 32608. \\ ${ }^{4}$ Zambia Wildlife Authority, Private Bag 1, Chilanga, Zambia /Zambia Carnivore Programme, P.O. Box 80, Mfuwe, \\ Eastern Province, Zambia / Department of Ecology, Montana State University, Bozeman, Montana, U.S.A., 59717 \\ ${ }^{5}$ South Luangwa Conservation Society, Mfuwe, Zambia
}

Received 31 July 2012. Accepted 4 December 2012

Little is known about gastrointestinal parasite infections in large carnivores in Africa and what is available is largely from East Africa. We collected faecal samples from nine spotted hyaenas (Crocuta crocuta), 15 lions (Panthera leo) and 13 African wild dog (Lycaon pictus) from Luangwa Valley, Zambia. The most common gastrointestinal parasites found were Isospora spp., Spirometra sp., Taeniidae and Sarcosystis spp. Twenty-eight per cent of all samples were co-infected with Spirometra sp. and Taeniidae, with co-infection rates highest among lions (67\%). Thirty-three per cent (3/9) of spotted hyaenas were infected with Isospora sp. Ninety-two per cent (12/13) of wild dog were infected with Sarcocystis, similar to results from studies in South Africa. One lion was infected with a parasite whose morphology suggested Strongyloides sp., not previously been reported in lions. Samples from one lion and two spotted hyaenas yielded no gastrointestinal parasites. Overall, parasite species were consistent with those found from studies in other regions of Africa and are likely a result of ingesting infected prey. To our knowledge this study provides the most comprehensive survey of gastrointestinal parasite infection in large carnivores from this region of Africa to date and provides baseline data for future studies.

Key words: Crocuta crocuta, gastrointestinal parasites, Lycaon pictus, Panthera leo, Zambia.

iven their large area requirements, inherently

Jlow densities, and susceptibility to human edge effects, large carnivore populations are in decline throughout Africa (Woodroffe \& Ginsberg

*Author for correspondence.

E-mail: are.r.berentsen@aphis.usda.gov

†Present address: 983 Highway 93 N, Carmen, Idaho, 83462, U.S.A
1998). However, an additional contributing factor is the influence of wildlife diseases. Some diseases, such as canine distemper and rabies, have received considerable attention (Cleaveland \& Dye 1995; Kat et al. 1996; Creel \& Creel 2002; Van de Bildt et al. 2002, among others). However, the prevalence of macroparasite infections in large carnivores has been largely overlooked. The interaction between parasite prevalence and intensity, physiological condition, and susceptibility to disease is well demonstrated in some species (see Samuel et al. 2001 for a review), but poorly understood in large carnivores. As these species are increasingly confined to fragmented landscapes in and around protected areas, obtaining a baseline of parasite loads can assist with disease management and conservation efforts.

Parasitic infections may reduce competitive fitness (Brassard et al. 1982; Scott 1988), influence population cycles (Hudson et al. 1998) and regulate host population abundance (Anderson \& May 1978). Often, parasitic infections tend to be over dispersed, to where many individual hosts have low parasite intensities and few individuals have high intensities of parasites (Scott 1988; MüllerGraf 1995; Junker et al. 2008). Thus, many animals may maintain low levels of infection whereas few actually succumb to disease. Furthermore, some wild canids have evolved to cope with a certain level of chronic parasitic infection that has little or no adverse health effects (Kennedy-Stoskopf 2003). 


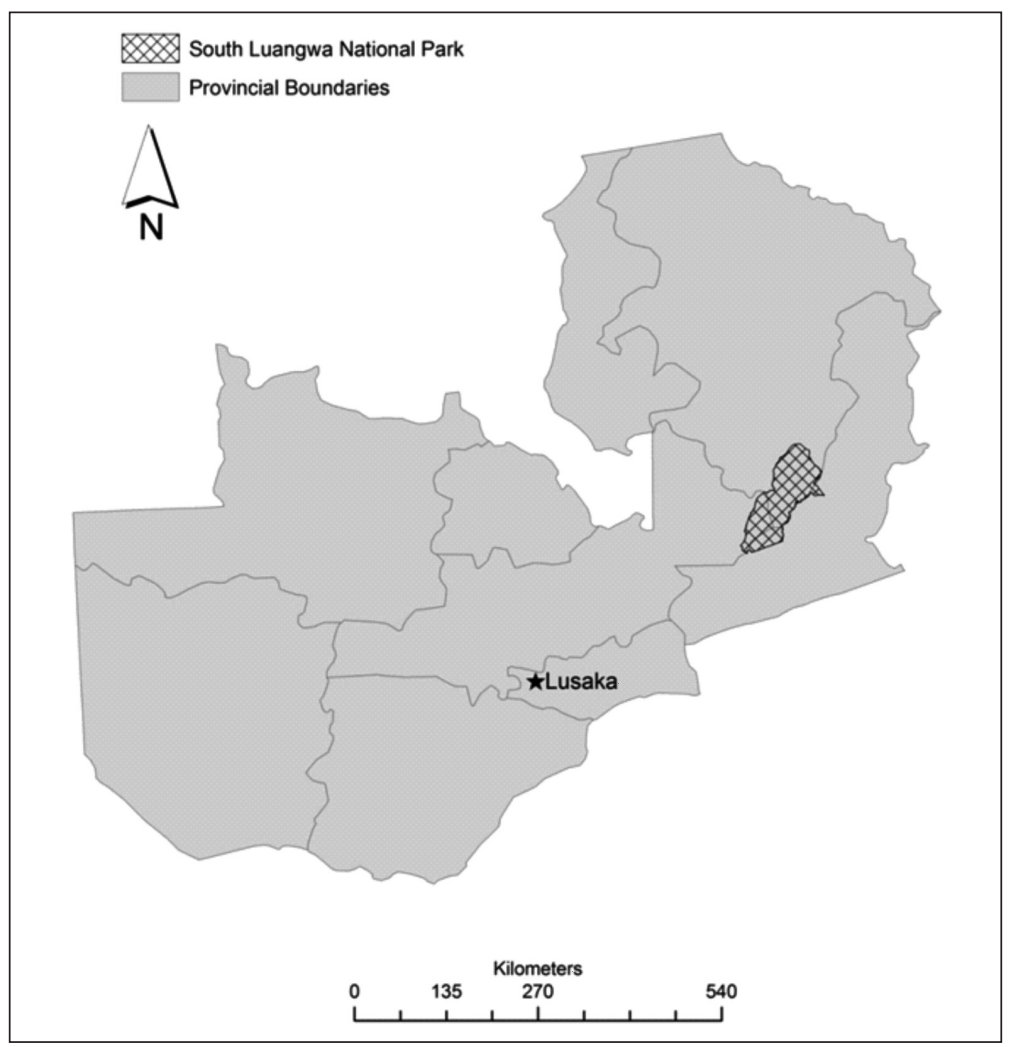

Fig. 1. Location of South Luangwa National Park, Zambia.

Data on internal parasite infections in large African carnivores are scant. Historically samples have been collected from captive animals (Geraghty et al. 1982; Ghoshal et al. 1988) or opportunistically from dead wild animals (LeRoux 1958; Rodgers 1974; Bwangamoi et al. 1990). Little information is available from live, free-ranging populations and what has been reported comes primarily from studies in East Africa (Müller-Graf 1995; MüllerGraf et al.1999; Bjork et al. 2000; Engh et al. 2003; Hüttner et al.2009). And while research into this topic has increased in recent years in southern Africa (Smith \& Kok 2006; Flacke et al. 2010), little is known regarding parasite prevalence from freeranging populations in much of the region. With approximately a third of its area managed for wildlife, Zambia still has viable populations of large carnivores such as lions (Panthera leo), African wild dogs (Lycaon pictus), and spotted hyaenas (Crocuta crocuta), particularly in the Luangwa valley. Wildlife populations in this region have been exposed to disease epizootics historically, primarily anthrax (Anthracis bacillus) (Turnbull et al. 1991). Nevertheless little information exists from Zambia on gastrointestinal parasites in carnivores beyond an early report from a private ranch in the Chinsali District in the former Northern Rhodesia (LeRoux 1958) and, more recently, a report of Giardia duodenalis in wild dogs (Ash et al. 2010).

Our objective was to obtain current data on gastrointestinal parasite infections in populations of African lions, spotted hyaenas and African wild dogs in the Luangwa valley, Eastern Zambia. To the best of our knowledge this study is the most comprehensive investigation into gastrointestinal parasite infections in large carnivores for this region and provides baseline information for future studies as well as valuable information on carnivore health.

Samples were collected in South Luangwa National Park (SLNP) and Lupande Game Management Area, which collectively cover approximately $13775 \mathrm{~km}^{2}$ (Fig. 1). The area is a mosaic of edaphic grassland, deciduous riparian forest, mopane (Colophospermum mopane) woodland, scrub woodland, miombo woodland, dry deciduous forest, and undifferentiated woodland 
Table 1. Prevalence of parasite ova, oocysts and larvae in the faeces of three carnivore species from the Luangwa Valley, Zambia.

\begin{tabular}{lccc}
\hline \multirow{2}{*}{ Parasite } & \multicolumn{3}{c}{ Prevalence } \\
\cline { 2 - 4 } & No. + Hyaenas (\%) & No. + Lions (\%) & No. + Wild dogs (\%) \\
\hline Unknown larvated nematode ova & $2^{*}(22)$ & $2^{*}(13)$ & $0(0)$ \\
Unknown trematode ova & $0(0)$ & $1(7)$ & $0(0)$ \\
Spirometra sp. & $2(22)$ & $13(87)$ & $1(8)$ \\
Isospora sp. & $3(33)$ & $0(0)$ & $1(8)$ \\
Dipylidium sp. & $2(22)$ & $0(0)$ & $0(0)$ \\
Taeniidae & $1(11)$ & $12(80)$ & $3(23)$ \\
Aelurostrongylus spp. larvae & $0(0)$ & $3(20)$ & $0(0)$ \\
Toxocara sp. & $0(0)$ & $2(13)$ & $0(0)$ \\
Sarcocystis sp. & $0(0)$ & $1(7)$ & $12(92)$ \\
No parasite ova seen & $2(22)$ & $1(7)$ & $0(0)$ \\
\hline
\end{tabular}

*Size and features suggest spiruroid nematode.

Characteristic single-folded larva suggest Strongyloides sp.

(Astle et al. 1969; White 1983; Astle 1988). The Luangwa River forms the eastern border for most of the park. A more detailed description can be found in Becker et al. (in press).

Faecal samples from carnivores were obtained opportunistically from 2009-2011 following observation of defecation or by direct collection during chemical immobilizations for snare removal or radio-collaring as part of ongoing studies of all three species. Carnivores were immobilized with a combination of tiletamine/zolazepan (Zoletil) and medetomidine (Domitor, Zolapene; Koch et al. 2006) and reversed with Atipamezole. All immobilization procedures followed animal welfare standards and protocols required by the Department of Veterinary and Livestock Development and the Zambia Wildlife Authority (ZAWA).

Faecal samples were fixed in neutral buffered $10 \%$ formalin or dried and refrigerated until shipped. Those faecal samples fixed in $10 \%$ formalin were evaluated using both Sheather's centrifugal flotation and centrifugal sedimentation methods (Zajac \& Conboy 2012). Dried faecal samples were rehydrated in tap water prior to flotation and evaluated by Sheather's centrifugal flotation methods. Modified McMaster's technique was used to calculate eggs per gram (EPG) of faeces for 12 formalin-fixed samples with sufficient amounts of faecal material ( $>1.0 \mathrm{~g}$ of faeces) (Zajac \& Conboy 2012). Remaining formalin-fixed samples containing sufficient ova counts after examination by faecal flotation or sedimentation were extrapolated to one gram to obtain theoretical EPG values (data not shown). Adult stages of parasites were not available. Samples only con- tained parasite ova, oocysts and/or larvae, therefore we were only able to identify most parasites to genus.

We obtained fresh faecal samples from nine hyaenas, 13 lions and seven wild dogs. Dried faecal samples from three lions (one dried faecal sample was from an individual lion from which fresh samples were also obtained) and six wild dogs were also examined (Table 1). No parasite ova, oocysts or larvae were recovered from two hyaenas and one lion.

Numerous Isospora spp. oocysts were recovered from three hyaenas. Unknown larvated nematode ova were recovered from two hyaenas, and Spirometra sp. and Dipylidium sp. ova were also recovered from two hyaenas. Taeniid ova were observed in one hyaena faecal sample. Isospora spp. oocysts have been reported in previous surveys of spotted hyaenas (Engh et al. 2003). In their report, oocysts were consistent with Isospora felis or I. leonina, at $35 \mu \mathrm{m}$ in size. The Isospora spp. oocysts found in the spotted hyaenas in our survey were slightly smaller $(25.3 \times 19.8-23 \mu \mathrm{m})$ or larger $(45.1 \times 22 \mu \mathrm{m})$ than previous findings and may represent two species based on our measurements. The unknown larvated nematode ova recovered from two hyaenas was most likely a spirurid based on size $(36.5 \times 16.5)$ and the characteristic thick outer shell. Spirurid ova of similar size have been previously reported in spotted hyaenas as consistent with Spirocerca lupi (Engh et al. 2003) and Cylicospirura subequalis (Round 1968). Spirometra sp. $(60.5 \times 30.8 \mu \mathrm{m})$ and Dipylidium sp. (packet: $104.5 \mu \mathrm{m}$; ovum: $39.4 \mu \mathrm{m}$ ) ova were also recovered, both of which have been 


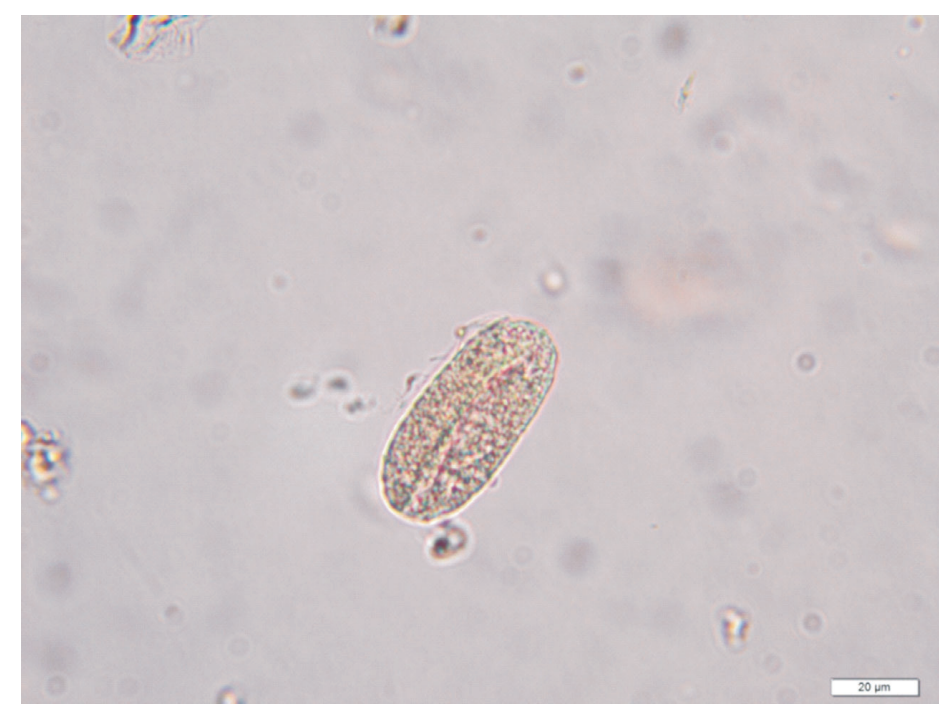

Fig. 2. Unknown nematode egg found in lion faecal sample. Morphology suggests Strongyloides.

previously found in spotted hyaenas (Engh et al. 2003; Round 1968). Overall, Spirometra pretoriensis is the most common species recovered from hyaenas (Müller-Graf 1995). Additionally, taeniid ova $(34.1 \mu \mathrm{m})$ were observed in a single hyaena faecal sample. Reported taeniid species in spotted hyaenas include Echinococcus granulosus, Taenia crocutae, T. hyaenae and T. serialis (Round 1968; Nelson et al. 1965).

When examining the lion faecal samples, Spirometra sp. ova were recovered from 13 samples, as well as Taeniid ova, which were recovered from 12 samples. Unknown larvated nematode ova were found in two lion faecal samples and unknown trematode ova were recovered from one lion faecal sample. Larvae of Aelurostrongylus spp. were found in three lion faecal samples. Additionally, Toxocara sp. ova were observed in two lion samples and a single lion sample contained Sarcocystis sp. sporocysts. The most prevalent parasite ova recovered from lions was Spirometra sp., which is a common finding (Round 1968; Müller-Graf 1995; Bjork et al. 2000) and generally thought to be Spirometra theileri. A single report indicated Spirometra okumurai was recovered from the intestine of one of six lions examined in southern Tanzania (Rodgers 1974). Taeniid cestodes were the second most common parasite found in our surveyed lions. Previous reports of taeniid species in lions suggests these ova could be Taenia regis, T. simba, T. gonyamai, T. taeniaformis, T. hydatigena or Echinococcus granulosus felidis (Nelson et al. 1965; Round 1968; Rodgers 1974; Young
1975; Jooste 1990; Müller-Graf 1995). The larvated nematode ova, based on size $(50.6 \times 22 \mu \mathrm{m})$ and evidence of a single-folded larva is most likely a Strongyloides species, not previously reported in lions (Fig. 2).

Unknown trematode ova were also recovered from a single lion faecal sample (Fig. 3). It is not clear whether this is a spurious finding or true parasite of the lion. Documentation of trematode ova recovered from lion faeces is rare, and the size $(74.8 \times 49.5 \mu \mathrm{m})$ and morphology of the trematode ova found in our survey does not correspond with previously reported findings which include Pharyngostomum cordatum or Paramphistomatidae (Round 1968; Müller-Graf 1995; Bjork et al. 2000). Both Toxocara cati and T. canis have been previously reported in lions (Round 1968; Müller-Graf 1995; Bjork et al. 2000) but the average size of the Toxocara sp. ova recovered in this survey $(76.5 \times 58 \mu \mathrm{m})$ is consistent with T. cati. Sarcocystis sp. is another commonly reported parasite found in lion faecal samples (Müller-Graf 1995; Bjork et al. 2000). The Sarcocystis sp. sporocysts in this survey were approximately $12.1 \times 7.7 \mu \mathrm{m}$ in size, corresponding to previous findings. Larvae are often recovered in lion faecal samples, and are most commonly Ollulanus tricuspis or Aelurostrongylus spp. (Round 1968; Müller-Graf 1995; Bjork et al. 2000). The larval stages recovered from lion faeces sampled in this survey had the characteristic kinky tail of Aelurostrongylus spp., morphologically distinct from $O$. tricuspis.

Nearly all of the wild dog faecal samples, 12 of 


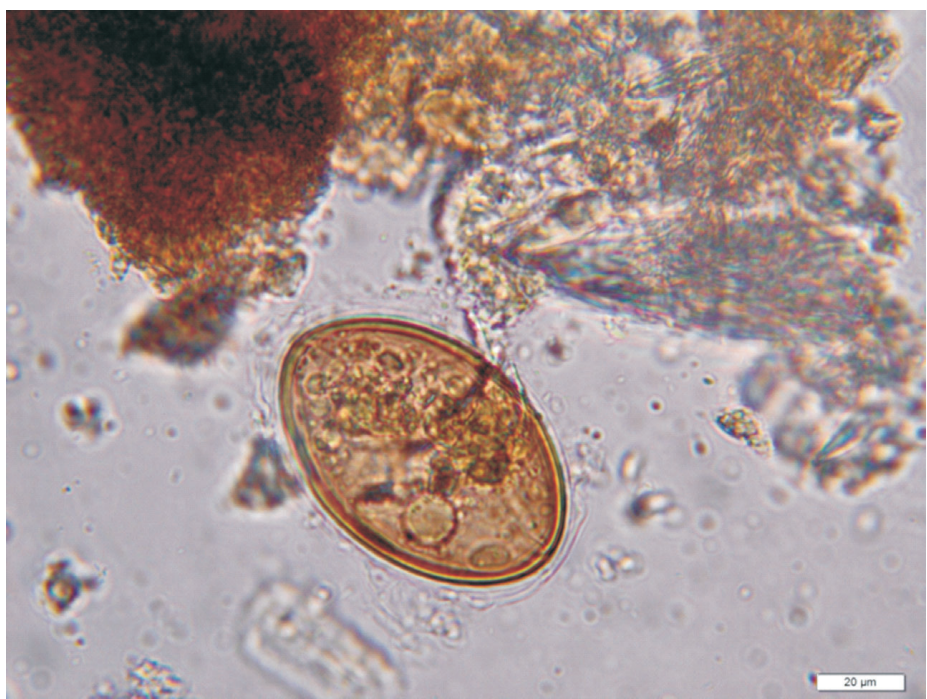

Fig. 3. Unknown trematode egg found in lion faecal sample.

$13(92 \%)$, contained Sarcocystis sp. sporocysts. Taeniid ova were recovered from three wild dog samples, followed by Spirometra sp. ova and Isospora sp. oocysts each found in one wild dog faecal sample. The most prevalent parasite observed in the faeces of wild dogs was the sporocysts of Sarcocystis sp., which was also reported in $100 \%$ of wild dogs surveyed in South Africa (Flacke et al., 2010). Taeniid ova $(32-36 \mu \mathrm{m})$ were also recovered from the wild dog faecal samples. Several taeniid species have been reported in wild dogs, including Echinococcus longimanubris, E. granulosus, E. granulosus lyacontus, Taenia hyaenae, T. brauni, T. lycaontis or T. pisiformis (Round 1968; Jooste 1990). Spirometra sp. ova was found in a single wild dog faecal sample and is most likely Spirometra pretoriensis based on previous reports from wild dogs in the Congo (Round 1968). Oocysts of Isospora spp. were also observed in one wild dog faecal sample, a genus recently identified in wild dogs from KwaZulu-Natal, South Africa (Flacke et al. 2010).

Forty-three per cent (16/37) of the animals sampled were co-infected with $\geq 2$ parasite species. Co-infection with multiple parasites was common in lions with $80 \%(12 / 15)$ of all lions sampled co-infected. Co-infection was less common in hyaenas and wild dogs with $3 / 9(33 \%)$ of hyaenas and 2/13 (15\%) wild dogs co-infected. The most common parasites responsible for co-infection were Spirometra sp. and Taeniida with 27\% (10/37) of all animals sampled co-infected with these two organisms.
Our results are consistent with reports from other regions of Africa regarding the prevalence and diversity of parasites recorded for lions, wild dogs and spotted hyaenas. The source of these parasites is likely from ingesting infected prey, although exactly which prey is responsible for individual parasites is unknown. Future research on this topic could provide valuable information on predator-prey dynamics and interspecific parasite transmission.

The authors wish to thank the Zambia Wildlife Authority and Department of Veterinary and Livestock Development for their permission and collaboration. Funding was provided by the Worldwide Fund for Nature-Netherlands and Painted Dog Conservation, Inc. Thanks to P. Bouley, C. Chirwa, E. Droge, C. Harrison, T. Mweetwa, F. Otten and E. Rosenblatt for field assistance.

\section{REFERENCES}

ANDERSON, R.M \& MAY, R.M. 1978. Regulation and stability of host-parasite population interactions: I. Regulatory processes. Journal of Animal Ecology 47: 219-247.

ASH, A., LYMBERY, A., LEMON, J., VIATLI, S. \& THOMPSON, R.C.A. 2010. Molecular epidemiology of Giardia duodenalis in an endangered carnivore - the African painted dog. Veterinary Parasitology 174: 206-212.

ASTLE, W.L. 1988. Republic of Zambia, South Luangwa National Park Map, landscape and vegetation. Lovell Johns, Oxford.

ASTLE, W.L., WEBSTER, R., LAWRANCE, C.J. 1969. Land classification for management planning in the Luangwa valley of Zambia. Journal of Applied Ecology 6: 143-169. 
BECKER, M.S., WATSON, F., DROGE, E., LEIGH, K., CARLONS, R. \& CARLSON, A.A. 2013. Estimating past and future male loss in three Zambian lion populations. Journal of Wildlife Management 77: 128-142.

BJORK, K.E., AVERBECK, G.A. \& STROMBERG, B.E. 2000. Parasites and parasite life stages of free ranging wild lions (Panthera leo) of northern Tanzania. Journal of Zoo and Wildlife Medicine 31: 56-61.

BRASSARD, P., RAU, M.E. \& CURTIS, M.A. 1982. Parasite induced susceptibility to predation in diplostomiasis. Parasitology 85: 495-501.

BWANGAMOI, O., ROTTCHER, D. \& WEKESA, L. 1990. Rabies, microbesnoitosis and sarcocystis in a lion. Veterinary Record 127: 411.

CLEAVELAND, S. \& DYE, C. 1995. Maintenance of a microparasite infecting several host species: rabies in the Serengeti. Parasitology 111: S33-S47.

CREEL, S. \& CREEL, N.M. 2002. Infectious diseases. In: The African Wild Dog: Behavior, Ecology and Conservation, pp. 269-287. Princeton University Press, Princeton, New Jersey, U.S.A.

ENGH, A.L., NELSON, K.G., PEEBLES, R., HERNANDEZ, A.D., HUBBARD, K.K. \& HOLEKAMP. K.E. 2003. Coprologic survey of parasites of spotted hyenas (Crocuta crocuta) in the Masai Mara National Reserve, Kenya. Journal of Wildlife Diseases 39: 224-227.

FLACKE, G., SPIERING, P., COOPER, D., GUNTHER, M.S., ROBERTSON, I., PALMER C. \& WARREN, K. 2010. A survey of internal parasites in free-ranging African wild dogs (Lycaon pictus) from KwaZuluNatal, South Africa. South African Journal of Wildlife Research 40: 176-180.

GERAGHTY, V., MOONEY, J. \& PIKE, K. 1982. A study of parasitic infections in mammals and birds at the Dublin Zoological Gardens. Veterinary Research Communications 5: 343-348.

GHOSHAL, S.B., GARG, U.K., MISARAULIA, K.S. \& JAIN, P.C. 1988. Helminth parasites in zoo animals of Kamla Nehru Park, Indore (MP). Livestock Adviser 13: 34-36

HUDSON, P.J., DOBSON A.P. \& NEWBORN, D. 1998. Prevention of population cycles by parasite removal. Science 282: 2256-2258.

HÜTTNER, M., SIEFERT, L., MACKENSTEDT, U. \& ROMIG, T. 2009. A survey of Echinococcus species in wild carnivores and livestock in East Africa. International Journal for Parasitology 39: 1269-1276.

JOOSTE, R. 1990. A checklist of the helminth parasites of the larger domestic and wild mammals of Zimbabwe. Transactions of the Zimbabwe Scientific Association 64: 15-32.

JUNKER, K., DEBUSHO, L. \& BOOMKER, J. 2008. The helminth community of helmeted guineafowls Numida meleagris (Linnaeus, 1758), in the north of Limpopo Province, South Africa. Onderstepoort Journal of Veterinary Research 75: 225-235.

KAT, P.W., ALEXANDER, K.A., SMITH, J.S. RICHARDSON, J.D. \& MUNSON, L. 1996. Rabies among African wild dogs (Lycaon pictus) in the Masai Mara, Kenya. Journal of Veterinary Diagnostic Investigation 8: 420-426.

KENNEDY-STOSKOPF, S. 2003. Canidae. In: Zoo and
Wild Animal Medicine, (eds) M.E. Fowler \& R.E. Miller, 5th edn, pp. 482-491. W.B. Saunders, St. Louis, MO.

KOCK, M.D., MELTZER, D. \& BURROUGHS, R. 2006. Chemical and Physical Restraint of Wild Animals. IWVS (Africa), Greyton, South Africa.

LEROUX, P.L. 1958. Pharungostomum cordatum (Dies, 1850), Galoncus perniciosus (v. Linstow, 1885) and Gnathostoma spinigerum (Owen, 1836), infections in a lion in Northern Rhodesia. Transactions of the Royal Society of Tropical Medicine and Hygiene 52:14.

MÜLLER-GRAF, C.D.M. 1995. A coprological survey of intestinal parasites of wild lions (Panthera leo) in the Serengeti and the Nogorongoro Crater, Tanzania, East Africa. Journal of Parasitology 81: 812-814.

MÜLLER-GRAF, C.D.M., WOOLHOUSE, M.E.J. \& PACKER, C. 1999. Epidemiology of an intestinal parasite (Spirometra sp.) in two populations of African lions (Panthera leo). Parasitology 118: 407-415.

NELSON, G.S., PESTER, F.R.N. \& RICKMAN, R. 1965. The significance of wild animals in the transmission of cestodes of medical importance in Kenya. Transactions of the Royal Society of Tropical Medicine and Hygiene 59: 507-524.

RODGERS, W.A. 1974. Weights, measurements and parasitic infestation of six lions from southern Tanzania. East African Wildlife Journal 12: 157-158.

ROUND, M.C. 1968. Checklist of the Helminth Parasites of African Mammals. CAB, Farnham Royal, Bucks, U.K.

SAMUEL, W.M., PYBUS, M.J. \& KOCAN, A.A. 2001. Parasitic diseases of wild mammals, 2nd edn. Blackwell Publishing, Ames, Iowa, U.S.A.

SCOTT, M.E. 1988. The impact of infection and disease on animal populations: implications for conservation biology. Conservation Biology 2: 40-56.

SMITH, Y. \& KOK, O.B. 2006. Faecal helminth egg and oocyst counts of a small population of African lions (Panthera leo) in the southwestern Kalahari, Namibia. Onderstepoort Journal of Veterinary Research 73: 71-75.

TURNBULL, P.C., BELL, R.H., SAIGAWA, K., MUNYENYEMBE, F.E., MULENGA, C.K. \& MAKALA, L.H. 1991. Anthrax in wildlife in the Luangwa valley, Zambia. Veterinary Record 128: 399-403.

VAN DE BILDT, M.W.G., KUIKEN, T., VISEE, A.M., LEMA, S., FITZJOHN, R.T. \& OSTERHAUS, D.M.E. 2002. Distemper outbreak and its effect on African wild dog conservation. Emerging Infectious Diseases 8: 211-213.

WHITE, F. 1983. The vegetation of Africa: a descriptive memoir to accompany the UNESCO/AETFAT/UNSO vegetation map of Africa. United Nations Educational, Scientific and Cultural Organization, Paris.

WOODROFFE, R. \& GINSBERG, J.R. 1998. Edge effects and the extinction of populations inside protected areas. Science 280: 2126-2128.

YOUNG, E. 1975. Some important parasitic and other diseases of lion, Panthera leo, in the Kruger National Park. Journal of the South African Veterinary Association 46: 181-183.

ZAJAC, A.M. \& CONBOY, G.A. 2012. Fecal examination for the diagnosis of parasitism. In: Veterinary Clinical Parasitology (8th edn). Wiley-Blackwell, Ames, Iowa, U.S.A. 